\title{
Entre o agendamento da mídia e o desinteresse: meio ambiente nas comunidades em rede de jovens"
}

\author{
Entre la programación de medios y el desinterés: \\ medioambiente en las comunidades de redes juveniles
}

\author{
Between Media Programming and Selflessness: \\ Environment in Youth Network Communities
}

\author{
Nathália Ronfini de Almeida Lima* \\ ORCID 0000-0001-6545-5127 \\ Universidade Federal do Rio de Janeiro
}

Milton N. Campos ORCID 0000-0003-3051-3985

Université de Montréal, Canadá

Recibido: 25 de noviembre de 2018 Revisado: 17 de junio de 2019 Aceptado: 10 de septiembre 2019

\section{Resumo}

Neste artigo, apresentamos um estudo de caso híbrido, qualitativo e quantitativo, que investigou o que os jovens entre 18 e 24 anos, no contexto psicossocial de baixa renda, no Grande Rio, Brasil, pensam a respeito do meio ambiente e como se expressam sobre isso no Facebook. Adotamos um quadro teórico que integra a Teoria da Ecologia dos Sentidos e os critérios de sustentabilidade. Combinamos a amostragem por critério e as técnicas de bola de neve para a escolha dos sujeitos. Buscamos entender, com base nas entrevistas semidirigidas e nos posts no Facebook, sentimentos, percepções e juízos dos jovens sobre questões ambientais. Destacamos que esses jovens manifestam interesse pela ecologia, mas postam com pouca frequência sobre o tema, não disponibilizam conteúdos criados por eles e contam com baixa adesão de amigos em suas comunidades do Facebook.

Palavras-chave: comunidades virtuais; Facebook; juventude; meio ambiente; redes sociais.

Artigo de pesquisa. Citar como: Ronfini de Almeida Lima, N. e Campos, M. N. (2020). Entre o agendamento da mídia e o desinteresse: meio ambiente nas comunidades em rede de jovens. Diversitas: Perspectivas en Psicología, 16(1), 37-53. Dol: https://doi.org/10.15332/22563067.4846 Correspondência: Nathália Ronfini de Almeida Lima, Universidade Federal do Rio de Janeiro, Brasil. E-mail: nathaliaronfini@gmail.com 


\section{Resumen}

En el artículo, se presenta un estudio de caso híbrido, cualitativo y cuantitativo, que investigó qué piensan los jóvenes entre 18 y 24 años, en el contexto psicosocial de bajos ingresos, en el Grande Rio, Brasil, sobre el medioambiente y cómo lo expresan en Facebook. Se adopta un marco teórico que integra la Teoría de la Ecología Sensorial y los criterios de sostenibilidad. Se combinan muestreo por criterio con técnicas de bola de nieve para la elección de asignaturas. Se buscó comprender, con base en entrevistas semiestructuradas y publicaciones de Facebook, sentimientos, percepciones y juicios de los jóvenes sobre cuestiones ambientales. Se evidencia estos jóvenes expresan interés en la ecología, pero publican con poca frecuencia sobre el tema, no proporcionan contenido creado por ellos y tienen poca adhesión de amigos en sus comunidades de Facebook.

Palabras clave: comunidades virtuales; Facebook; juventud; medio ambiente; redes sociales.

\section{Abstract}

This article presents a hybrid case study (qualitative and quantitative) on what young people (18 to 24-year-old) in the low income psychosocial context of the Rio de Janeiro metropolitan area, Brazil, think about the environment and express themselves with regard to this topic on Facebook. An integrated theoretical framework weaving the Ecology of Meanings theory and sustainability criteria was adopted. We sought to understand the youths' feelings, perceptions and judgment about the environment through semi-structured interviews and Facebook postings. Results suggest that although youngsters do have an interest on ecology, postings about it are limited, content created by them is not disseminated, and friends from Facebook communities have little interest in the subject.

Keywords: youth; environment; social networks; virtual communities; Facebook.

\section{Introdução}

As questões ambientais parecem distantes da vida cotidiana dos jovens de baixa renda do Grande Rio, segundo maior aglomerado urbano do Brasil. Apesar de sofrer com a violência, a baixa mobilidade urbana (Pero e Mihessen, 2013) e a saúde pública em crise (Puff, 2016), essa juventude parece calar-se quando o assunto é meio ambiente. As "águas de março" que fecham o verão e que têm se intensificado, trazendo rastro de morte e destruição (Castilho, Oliveira e Fabriani, 2012), principalmente nas áreas socialmente abandonadas pelo Estado, não parecem mudar essa percepção. As mudanças climáticas, um dos maiores problemas causados pela ação antrópica (Painel Intergovenamental sobre Mudanças Climáticas, 2012), não parecem sensibilizar a geração ameaçada que vai herdar o Grande Rio do futuro.
Devido à limitação de trabalhos científicos sobre o tema, neste artigo, argumentamos ser pertinente averiguar o que a juventude de baixa renda pensa sobre questões ambientais e se esses jovens - os que mais sofrem com as mazelas do desequilíbrio ecológico - estão sensibilizados para o problema. $\mathrm{Na}$ busca de respostas, escolhemos a rede Facebook para avaliar se discutem a respeito do meio ambiente e como se expressam sobre isso.

\section{Uma geração entre a crise socioambiental e o futuro}

Apesar da relevância social de pesquisas que discutem juventude, comunidades em rede ou meio ambiente e ação política, a produção científica apresenta uma lacuna evidente relativa ao entrelaçamento desses três temas. Como a participação 
jovem nas redes desvela novas formas de atuação política, acreditamos que esse debate seja fundamental para que possamos compreender melhor o mundo contemporâneo, com o objetivo de transformá-lo. Nesta seção, discutiremos esses três temas.

\section{Juventude}

Tema de diversas pesquisas, ainda não há um consenso em torno de uma definição de "juventude". Alguns autores, inclusive, não a relacionam à idade de uma maneira estrita. A respeito dessa indefinição, Zanella e colaboradoras (2013) destacam que estudiosos a entendem como sinônimo exclusivo de adolescência. Outros não se limitam a esse período, como é o caso de Silva e Silva (2011). Estes autores destacam que a juventude é comumente caracterizada como a "fase de transição entre a adolescência e a vida adulta" (p. 664).

Matos (2012) é mais específico ao destacar que a maior parte dos organismos internacionais, inclusive a Unesco, entendem a juventude como o período compreendido entre os 15 e os 24 anos de idade, embora essa fase possa ser estendida até os 29 anos em países com alto grau de desigualdades sociais, como o Brasil. As definições estão, geralmente, relacionadas com a entrada no mercado de trabalho. $\mathrm{O}$ fenômeno do alongamento da juventude até os 29 anos, por exemplo, se dá em alguns países da Europa por conta da moratória social imposta pela dificuldade de colocação profissional após a conclusão dos estudos. 0 outro lado dessa moeda é o adiantamento da juventude para antes dos 15 anos, definido no Brasil por conta da necessidade de inserção prematura no mercado de trabalho e da independência precoce dos jovens de baixa renda (Baubay e Gerber, 1996; Chamborendon, 1995; Müxel, 1994 como citado em Sposito, 1997).

Margulis e Urresti (2008), por sua vez, adotam uma perspectiva mais abrangente sobre o que vem a ser juventude. Os pesquisadores rompem as dicotomias entre os autores que a fixam em uma faixa etária e aqueles que entendem apenas as questões socioculturais como determinantes para a sua definição. Embora concordem com Bourdieu (1983), na medida em que assumem que a juventude seria uma construção social que vai além da questão etária, acrescentam que as questões biológicas também fazem parte dessa fase, o que traz um novo prisma para a discussão.

\section{Comunidades em rede}

As comunidades em rede são grupos de interesse que se reúnem virtualmente por meio de plataformas disponibilizadas na internet, ainda que se reúnam também de forma presencial (Lévy, 1999). Hoje, os jovens com idades entre 15 e 24 anos são os segundos maiores usuários do Facebook no Brasil, um total de $22.4 \%$, ficando atrás apenas dos que estão entre 25 e 34 anos, que representam 23.2\% (Banks, 2015).

Robards e Bennett (2011) apontam que as redes sociais parecem não reconfigurar as relações sociais ou os sistemas de identidade e pertencimento, mas sim evidenciar aspectos da vida cotidiana e práticas sociais já existentes. Segundo os autores, embora as novas tecnologias de comunicação possam conectar pessoas de quaisquer partes do mundo, os usuários de redes como Facebook usam esse canal para manter contato com pessoas que já conhecem e com quem já mantêm um contato face a face (amigos, familiares, colegas de trabalho) do que para estabelecer novos relacionamentos. Convergindo com o pensamento de Robards e Bennet (2014), Ellison, Steinfield e Lampe (2007) e Recuero (2014) reforçam que as redes sociais proporcionam novas formas de conexão e espaços de produção de capital social: quanto mais conexões, mais capital. Redes como o Facebook produziriam capital social de manutenção, ou seja, que contribui para reforçar as relações sociais já existentes. Também defendendo essa rede como espaço de manutenção de vínculos sociais, Pempek, Yarmoleyeva e Calvert (2009), assim como Ross e colaboradores (2009), indicam que a juventude usa essa rede para falar com amigos antigos. O próprio Facebook, aliás, foi desenvolvido em 2004 com o objetivo de criar e manter vínculos sociais entre estudantes locais da Harvard University (Ellison, Steinfield e Lampe, 2007). Antes mesmo da criação do Facebook e da web 2.0, Wellman e colaboradores (2001a) já destacavam que as interações on-line complementavam as interações face a face. 


\section{Meio ambiente e ação política presencial e nas redes}

No Brasil, estudos sobre as ações políticas da juventude parecem ter sido iniciados por Foracchi (1965), que se debruçou sobre os movimentos estudantis da década de 1960. Nas décadas seguintes, o tema gerou poucos debates. Incipientes, foram deixando de ser realizados possivelmente por falta de mobilização jovem. Esse hiato foi interrompido nos anos 1980 e 1990, segundo as reflexões de Abramo (1997). A pesquisadora, que investigou o cenário jovem nesse período, discute criticamente o entendimento de mobilização juvenil apresentado em trabalhos anteriores de outros autores ao propor formas alternativas de compreendê-la, como a atuação nas esferas do comportamento e da cultura.

Conforme destaca Matos (2012), no Brasil, a participação dos jovens nos movimentos ambientais é histórica. Entretanto, a sua representatividade, segundo a autora, não se forjava, no passado, por meio de grupos engajados com questões ambientais, mas por jovens independentes que se integravam a movimentos ecológicos. Essa característica mudou com o advento da Constituição de 1988 e com a Eco-92, porque a questão ambiental passou a fazer parte da pauta de diversos setores e grupos sociais (Matos, 2012). A pesquisadora destaca ainda que, a partir da década de 1990, quando órgãos internacionais, movimentos juvenis e pesquisadores passaram a manifestar, cada vez mais, interesse pelas questões da juventude, o meio ambiente passou a ganhar mais destaque.

Desde então, uma das formas de mobilização jovem, no que diz respeito ao meio ambiente, é a educação. Pesquisas que investigaram em que medida a educação ambiental fomenta a participação social efetiva e consciente dos jovens, promovendo a cidadania, foram documentadas. Matos (2012), por exemplo, reforça o potencial da educação ambiental não formal como importante meio para a mudança do comportamento juvenil. Sobre isso, a autora destaca o papel mobilizador fundamental das Conferências Nacionais Infanto-Juvenis pelo Meio Ambiente e da Política Nacional de Educação Ambiental, criada em 2003. A esse respeito, Zanella e colaboradoras (2013) ressaltam que temas como políticas públicas para a juventude e empoderamento foram se destacando nas pesquisas nacionais por conta da Política Nacional de Juventude, criada em 2006, e do Estatuto da Juventude, lançado em 2013. Além disso, o protagonismo jovem no que tange às discussões ambientais emergiu com mais força a partir da criação do Plano Nacional de Juventude e Meio Ambiente de 2013. Entre suas diretrizes, o plano integrava, também, a Política Nacional de Educação Ambiental, criada em 1999. Calado e Camarotti (2013) também relatam uma experiência nacional bem-sucedida, realizada no município de Borborema, localizado no brejo paraibano, Brasil: o Programa Projovem Adolescente. Criada pelo governo federal para amparar adolescentes de famílias beneficiadas pelo Programa Bolsa Família, essa iniciativa de educação ambiental fomentada por políticas públicas, segundo o relato das autoras, gerou ações engajadas de jovens da região, o que ampliou processos de sociabilidade.

Além da questão da sociabilidade presencial, as redes sociais têm se transformado em espaços de participação na reivindicação por causas socioambientais que os jovens consideram relevantes. A juventude, por conta de seu caráter historicamente contestador (Viana, 2010), vem assumindo, de forma progressiva, o protagonismo em manifestações políticas como as que ocorreram nas principais capitais brasileiras, em 2013, na época dos grandes eventos esportivos no Rio de Janeiro (Burg, Ronfini e Campos, 2017). Organizado em torno de protestos contra o aumento das passagens de ônibus, esse movimento marcadamente liderado pela juventude levou a outras reivindicações, fomentadas e reverberadas por meio das redes (Peruzzo, 2013). O caso do coletivo jovem \#OcupaAlemão, estudado entre 2013 e 2014, por Silva e Gonzales (2016), é exemplar. 0 grupo, ainda ativo, propõe soluções para os problemas do Rio de Janeiro por meio do Facebook, com discussões presenciais e virtuais. As autoras sinalizam que a interação digital pode contribuir para a formação de cidadãos participativos. Entretanto, seriam também necessárias orientações compartilhadas tanto em suas redes sociais off-line como nas redes sociais das quais participam (Silva e Gonzales, 2016).

Apesar de as comunidades em rede, particularmente as formadas a partir do Facebook, serem foco 
de debates múltiplos, pouco sabemos se os jovens discutem a respeito do meio ambiente e como se expressam sobre isso. Pinheiro (2013), por exemplo, aborda a questão da participação jovem via Twitter na conferência Rio+20, do consumo verde. Avaliando o perfil @JuventudeRio20, com centenas de seguidores, a autora descobriu que as palavraschave mais recorrentes nas trocas digitais foram "protagonismo", “consumo", "sustentabilidade", "identificação" e "empoderamento". Comparada à ECo-92, a Rio+20 teve maior participação popular tanto nos eventos quanto em redes sociais como Twitter e Facebook. Esse trabalho parece sugerir que a juventude assume progressivamente um protagonismo a respeito de discussões sobre o meio ambiente em comunidades em rede.

\section{Sentimentos, percepções e juízos da juventude em relação à problemática socioambiental}

Nossa reflexão a respeito dos temas sobre os quais acabamos de discorrer levou-nos às seguintes questões: a juventude atual discute em rede o meio ambiente? Os jovens de baixa renda estão sensibilizados para esse problema? Em resumo: o que sentem, quais são suas percepções e quais juízos estabelecem a respeito do meio ambiente? Nesse sentido, como exposto, desenvolvemos uma pesquisa com jovens de 18 a 24 anos, de baixa renda do Grande Rio, habituados a compartilhar suas ideias pelo Facebook.

\section{Integrando a Ecologia dos Sentidos com critérios de sustentabilidade}

\section{Ecologia dos Sentidos}

A Ecologia dos Sentidos é uma teoria transdisciplinar de orientação construtivisto-crítica que apresenta uma abordagem psicossocial da comunicação. Com o objetivo de estudar a natureza das trocas, relaciona fenômenos da natureza - fatos que emergem da condição biológica do ser humano e dos grupos sociais, ou seja, da adaptação psicossocial ambiental - e da cultura - traços derivados de percursos subjetivos individuais e de histórias coletivas em função das trocas intersubjetivas ocorrentes segundo as condições materiais de existência, ou seja, da adaptação psicossocial histórico-cultural (Burg et al., 2017). Nesse sentido, embora a comunicação, no ser humano, se constitua nas trocas culturais, também é de ordem natural na medida em que o desenvolvimento das estruturas cognitivas e afetivas, e dos mecanismos de construção simbólica (que permitem a fala e a escrita, as produções midiáticas etc.) têm uma inscrição sociobiológica. A Ecologia dos Sentidos prevê, portanto, em seu corpo conceitual, a problemática das relações entre sujeitos, grupos e sociedades, em processos comunicativos de adaptação ao meio ambiente natural, de um lado, e à história e à cultura, de outro.

No que diz respeito à tecnologia, a teoria permite compreender as ferramentas digitais como "lentes" tecnológicas que reconfiguram histórica e culturalmente as formas "naturais" de comunicação psicossocial. Em outras palavras, as interações psicossociais, quando mediadas pela tecnologia, se dão de acordo com as possibilidades de meios específicos, devendo ser compreendidas em suas dimensões ambientais e histórico-culturais. Logo, o design tecnológico tem consequências: o uso do Facebook, como lente mediadora, reconfigura tecnologicamente as trocas psicossociais de modo diferente das que ocorreriam por meio do Twitter ou do Instagram. As conversas presenciais, face a face, contam com as trocas de olhares, gesticulação, tom de voz etc. que produzem sentidos e se fundem ao discurso. Nas interações em redes sociais, ainda que esses recursos expressivos estejam ausentes, as tecnologias se integram progressivamente (nas comunicações por vídeo, por exemplo). Nas trocas pelas redes, novos recursos são progressivamente criados, de modo que memes, emoticons e emojis, por exemplo, contribuem, de certa maneira, para a reconfiguração do processo comunicativo psicossocial.

Essa teoria nos ajudou a entender se o Facebook potencializou ou limitou trocas sobre o meio ambiente em jovens constituídos cognitiva e afetivamente, histórica e culturalmente, de uma determinada maneira. Ou seja, por meio das suas configurações de 
sentidos que emergem de suas imagens do mundo (representações individuais e sociais).

\section{Critérios de sustentabilidade}

De acordo com o relatório "Situação da População Mundial 2014", produzido pelo Fundo de População das Nações Unidas (2014), dos 1,8 bilhão de adolescentes e jovens (entre 15 e 24 de idade) de todo o mundo, aproximadamente 515 milhões viviam, na época, abaixo da linha da pobreza, com menos de dois dólares por dia. Isso significa dizer que quase um terço dessa população se encontra em situação de vulnerabilidade social (ONU Brasil, 2014). Excluídos do sistema capitalista global de consumo, são parte do refugo humano a que refere Bauman (2005). Em vista disso, não é de se espantar que haja disputas econômicas, políticas e simbólicas em jogo nas definições de sustentabilidade que são propostas.

A definição mais frequentemente utilizada é a trazida pelo Relatório Brundtland, com foco na manutenção dos padrões humanos de consumo. Ela afirma que o "desenvolvimento sustentável é aquele que possibilita satisfazer as necessidades do presente sem comprometer a possibilidade das gerações futuras de satisfazer suas próprias necessidades" (World Commission on Environment and Development, 1987, p. 61). Já na visão de Sachs (2002), que adotamos na nossa pesquisa por ser coerente com nosso quadro teórico, além de ser menos conservadora, dá ênfase aos aspectos mais relevantes de cada um dos critérios para a sustentabilidade: (1) "social", que inclui a distribuição de renda justa e igualdade no acesso a recursos; (2) "cultural", que não impõe modelos de fora; (3) "ecológica", que preserva a natureza e garante os recursos renováveis, bem como racionaliza o uso dos não renováveis; (4) "ambiental", que respeita o tempo de restauração dos sistemas; (5) "territorial", que equilibra as configurações urbanas e rurais, e conservação pelo ecodesenvolvimento; (6) "econômica", que promove a inserção soberana internacional e garante a segurança alimentar; (7) "política nacional", que mantém democracias alinhadas com os Direitos Humanos; (8) "política internacional", que promove a paz e a cooperação, com a prevenção de guerras.

\section{Olhar integrativo}

Adotamos, portanto, a Ecologia dos Sentidos (Campos, 2015a, 2015b, 2017; Campos e Grabovschi, 2011) por ser uma teoria que integra meio ambiente e sociedade em processos de desenvolvimento ecológico, e as oito dimensões da sustentabilidade, segundo Sachs (2002). Suas imbricações orientaram a análise dos dados que recolhemos para responder às questões de pesquisa.

\section{Metodologia: um estudo de caso de comunidades jovens no Facebook}

\section{Método}

Realizamos um estudo de caso híbrido, em que dados quantitativos e qualitativos foram integrados. Segundo Yin (2001), "um estudo de caso é uma investigação empírica que investiga um fenômeno contemporâneo dentro de seu contexto da vida real, especialmente quando os limites entre o fenômeno e o contexto não estão claramente definidos [...]" (p. 32). Apesar de os resultados se basearem fundamentalmente na parte qualitativa, de orientação interpretativo-crítica, a dimensão quantitativa foi crucial para dar início à pesquisa, além de propiciar credibilidade, na última fase, por meio de uma análise das "linhas do tempo" do Facebook.

\section{Sujeitos da pesquisa e amostragem}

Os sujeitos da pesquisa são jovens de 18 a 24 anos, que correspondem à segunda faixa da população economicamente ativa, de acordo com o Instituto Brasileiro de Geografia Estatística ([s.d.]), única faixa que apresenta exclusivamente jovens que já são maiores de idade. 0 perfil de baixa renda foi alcançado no processo de amostragem.

A amostragem foi feita em duas etapas. Na primeira, 10.427 alunos e ex-alunos do pré-vestibular social (PVs) da Fundação Centro de Ciências e Educação Superior a Distância do Estado do Rio de Janeiro (Cecierj) foram contatados. Preparatório a provas de seleção à graduação, o pvs é um curso que apli- 
ca critérios de seleção social para jovens de baixa renda (Fundação Cecierj e consórcio Cederj, [s.d.]). Os jovens foram convidados, por meio de uma plataforma de pesquisa, a responder se aceitavam serem entrevistados. Os que responderam positivamente receberam, de nossa parte, um "convite de amizade" pelo Facebook (alguns foram pelo WhatsApp e pelo Instagram). Obtivemos 66 respostas, e 40 foram contatados para dar início à fase seguinte.

Na segunda etapa, adotamos uma combinação de amostragem por critério (Freitas et al., 2000) e bola de neve (snowball). A amostragem por critério é baseada na escolha arbitrária de grupos predefinidos (Sandelowski, 2000). Com o critério de "baixa renda", lançamos a snowball. Jovens de baixa renda do Grande Rio foram solicitados a indicar outros de suas redes de relacionamento que, por sua vez, convidaram outros, de modo que a "bola de neve" foi crescendo (Handcock e Gile, 2011). Para Baltar e Brunet (2012), essa técnica ajuda a contatar indivíduos difíceis de alcançar. A definição final do número de entrevistados (14 jovens: 8 mulheres $\mathrm{e}$ 6 homens) foi determinada ao longo da análise dos dados de dezenas de jovens, pelo critério conhecido como "ponto de saturação". Segundo Glaser e Strauss (1967), este se caracteriza quando a repetição de fatos e ideias pelos participantes indica que novos dados não estão sendo mais encontrados. Aos dados remanescentes, aplicamos categorias teóricas (veja Figura 1).

\section{Instrumentos de coleta de dados e triangulação}

Foram conduzidas (1) entrevistas semiestruturadas, por meio de videochamada via Facebook e trocas de áudio por WhatsApp, além de (2) observação das interações nas "linhas do tempo" e de seus perfis. Segundo Facebook ([s.d.]), "a linha do tempo é onde você pode ver suas publicações ou as publicações em que você foi marcado organizadas por data" (s. p.).As entrevistas semiestruturadas contam com respostas abertas, mas têm direcionamento que vai ao encontro dos objetivos da pesquisa (Manzini, 2003, 2004, 2012). A maior parte foi realizada pelo Facebook, mas algumas, em função de problemas técnicos, foram refeitas por meio do WhatsApp.
Ademais, observamos as interações visíveis nas "linhas do tempo", durante seis meses (de julho a dezembro de 2017). Identificamos e analisamos apenas as postagens relacionadas com o meio ambiente. Estudamos compartilhamentos, comentários, curtidas e suas derivações ("amei", "haha", "uau", "triste", "grr" etc.).

Os dados quantitativos e qualitativos foram triangulados no processo de análise e interpretação. A triangulação é uma técnica que consiste na obtenção de dados de diversas fontes, o que promove um cruzamento entre elas (Yin, 2001).

\section{Estratégia de análise e interpretação dos dados}

Esse processo foi realizado em duas etapas: (1) análise lógico-natural das trocas e (2) classificação do material segundo um modelo integrativo teórico.

\section{Primeira etapa}

Aplicamos aos discursos selecionados a análise lógico-natural. Explicar esse procedimento ultrapassa os objetivos deste artigo. Em resumo, a lógica natural foi desenvolvida pelo semiólogo, comunicólogo e lógico suíço Jean-Blaise Grize com o objetivo, entre outros, de fornecer uma ferramenta rigorosa de análise do discurso cotidiano. Ela permite a extração de representações - entendidas aqui como "imagens do mundo" - e a interpretação das configurações de sentidos por meio da identificação de objetos e operações que constituem os discursos, levando em conta o caráter intersubjetivo da comunicação (Grize, 1996, 1997). As letras gregas que aparecem no primeiro quadro da Figura 2 exemplificam as diferentes operações dessa metodologia de análise discursiva (Campos, 2015a, 2015b, 2017; Campos e Grabovschi, 2011).

\section{Segunda etapa}

Após a análise e interpretação lógico-natural do discurso, buscamos (1) categorizar suas unidades de acordo com os critérios de sustentabilidade de Sachs (2002) e (2) com três vértices da Ecologia dos Sentidos: as estruturas cognitivas e afetivas do 
sujeito; a consciência, a vontade e a moralidade, e as condições materiais de existência.

$\mathrm{Na}$ coluna do meio (Figura 1, entre as colunas esquerda e direita), indicamos as questões a serem mapeadas: a afetividade e os sentimentos envolvi- dos nas percepções dos jovens; os juízos normativos que partem de suas percepções para fundamentar seus argumentos em rede, e a influência que o contexto ambiental (territorial, social, econômico e político) exerce no seu cotidiano.

\begin{tabular}{|c|}
\hline $\begin{array}{c}\text { Critérios para a susten- } \\
\text { tabilidade, de acordo } \\
\text { com Sachs }\end{array}$ \\
\hline $\begin{array}{c}\text { Localizar, nos discursos, } \\
\text { onde aparecem }\end{array}$ \\
\hline Social \\
\hline Cultural \\
\hline Ecológico \\
\hline Ambiental \\
\hline Territorial \\
\hline Econômico \\
\hline Político (nacional) \\
\hline Político (internacional) \\
\hline
\end{tabular}

\begin{tabular}{|c|}
\hline Questões derivadas \\
\cline { 1 - 1 } Mapear \\
$\begin{array}{c}\text { Sentimentos e } \\
\text { percepções } \\
\text { questões }\end{array}$ \\
\hline Juízos \\
\hline $\begin{array}{c}\text { Contexto ambiental } \\
\text { (territorial, social e } \\
\text { político) }\end{array}$ \\
\hline
\end{tabular}

\begin{tabular}{|c|}
\hline $\begin{array}{c}\text { Vértices da Ecologia } \\
\text { dos Sentidos que } \\
\text { possibilitam as visões } \\
\text { de mundo }\end{array}$ \\
\hline $\begin{array}{c}\text { Estruturas cognitivas e } \\
\text { efetivas do sujeito } \\
\text { Consciência, vontade e } \\
\text { moralidade }\end{array}$ \\
\hline $\begin{array}{c}\text { Condições materiais de } \\
\text { existências }\end{array}$ \\
\hline
\end{tabular}

Figura 1. Modelo que integra os oito critérios de sustentabilidade e a Ecologia dos Sentidos.

Fonte: adaptado de Ronfini (2018, p. 56).

Abaixo, na Figura 2, o quadro completo de análise e interpretação discursiva.

\begin{tabular}{c} 
a (alfa) \\
Define os objetos sobre os quais se fala \\
$\tau(\mathrm{tau})$ \\
\hline
\end{tabular}

Produz configurações de sentidos a partir da articulação de enunciados

( 11$)$ Olha, eu posto. Só que eu não lembro a última coisa que postei... Posto tanta coisa! Mas, geralmente sempre rola alguma coisa... A última coisa que compartilhei sobre meio ambiente foi... Amazônia? Mata Atlântica? Não lembro... Ahhhh, do desmatamento. Algum lance... não lembro... Não lembro... Algum lance que Temer queria fazer. Não lembro... Não lembro... Era algum lance sobre o desmatamento que o governo queria fazer. E teve um pessoal fazendo uma petição, sei lá, um abaixo-assinado para o Temer não fazer. Botei no Facebook tem um tempinho. Aquele caso de Mariana lembro que eu postei muito também. Aquilo, nossa! Aqui foi muito pesado... fiz um trabalho também sobre aquilo em 2015. Em 2015, eu postei muito sobre o meio ambiente, ainda mais depois do que aconteceu naquela tragédia de Mariana. Mas a última recente foi sobre o desmatamento.

( 2 2) A minha motivação é... A gente tem que preservar o que é nosso. Para mim, é isso. Tipo isso... se conscientizar sobre o meio ambiente, preservar. Então, o que me motiva a postar é, tipo...

(†3) é sacanagem... tipo, eu vou falar: é sacanagem essas pessoas que têm o lixo ao lado delas e jogam na rua. Tipo, cara, tem um lixo do teu lado! Por que você vai jogar na rua? [Trecho inaudível de aproximadamente 10 segundos]

(ז4) Tipo, eu detesto ver animal sofrendo. Detesto ver animal sofrendo! Detesto! Me dá um treco no coração! Dá vontade de pegar o bichinho e colocar no lugar dele. Eu não gosto que maltratem o animal.

(ז5) No Facebook tem aquelas carinhas: feliz, alegre, triste, raiva... Aí, nas postagens, colocam raiva, outros não colocam nada. Uns colocam triste... é mais ou menos isso. Eles reagem dessa maneira.

(†5) Não... Não! Geralmente meus amigos não comentam sobre. Só as pessoas com que não tenho muito contato, muita intimidade. [Trecho inaudível de aproximadamente 3 segundos]

(๘6) Olha, acredito! A internet é um meio... Tipo o YouTube. No YouTube, você pode botar alguma coisa e de repente alguém do outro lado do mundo já sabe. Tipo, então falar na internet, principalmente sobre meio ambiente, ajuda muito! Tipo, a petição que eu falei do desmatamento, nossa, rodou muito no meu Facebook, e tipo, uau! Eu compartilhei e todo mundo compartilhou também. Eu carregava muita gente que ia. Acho que a internet é o meio pra você divulgar, para você problematizar as coisas também. 


\begin{tabular}{l|c|c|c|c|c|c|c|c|}
\hline \multicolumn{7}{|c|}{ Critérios da sustentabilidade presentes } \\
\cline { 3 - 9 }
\end{tabular}

\begin{tabular}{|c|c|c|}
\hline \multicolumn{3}{|c|}{ Ecologia dos Sentidos } \\
\hline $\begin{array}{l}\text { Sentimentos } \\
\text { e perce- } \\
\text { pções }\end{array}$ & Juízos & $\begin{array}{c}\text { Contexto } \\
\text { ambiental } \\
\text { (territorial, } \\
\text { social e } \\
\text { político) }\end{array}$ \\
\hline $\begin{array}{l}\text { Odeia que } \\
\text { maltratem os } \\
\text { bichos. } \\
\text { Achou “pesa- } \\
\text { do" o caso de } \\
\text { Mariana. } \\
\text { Expressa } \\
\text { indignação a } \\
\text { respeito de } \\
\text { pessoas que } \\
\text { não jogam o } \\
\text { lixo no lugar } \\
\text { correto. }\end{array}$ & $\begin{array}{l}\text { Os amigos dela } \\
\text { não são tão } \\
\text { ativos em todas } \\
\text { as postagens } \\
\text { sobre o meio } \\
\text { ambiente, ape- } \\
\text { nas as pessoas } \\
\text { com quem ela } \\
\text { não tem muita } \\
\text { intimidade. } \\
\text { A petição sobre } \\
\text { o desmata- } \\
\text { mento que ela } \\
\text { compartilhou } \\
\text { e que gerou } \\
\text { muita adesão } \\
\text { entre os amigos } \\
\text { dela. } \\
\text { As redes sociais } \\
\text { são espaço para } \\
\text { a discussão e } \\
\text { a problemati- } \\
\text { zação por po- } \\
\text { derem chegar } \\
\text { a pessoas de } \\
\text { qualquer lugar } \\
\text { do mundo. }\end{array}$ & $\begin{array}{l}\text { Menciona a } \\
\text { questão do } \\
\text { desmata- } \\
\text { mento e da } \\
\text { ligação do } \\
\text { tema com } \\
\text { o governo } \\
\text { Temer. }\end{array}$ \\
\hline
\end{tabular}

Figura 2. Exemplo de utilização do quadro de análise e interpretação.

Fonte: adaptado de Ronfini (2018, p. 64).

\section{Terceira etapa}

Finalmente, fizemos a análise da linha do tempo do Facebook (ver exemplo de aplicação na Figura 3). Levamos em consideração o número total de postagens sobre questões ambientais; de "amigos" no Facebook (informação que serviu para se chegar ao percentual de "amigos" envolvidos e padrões quantitativos de interação); de interações, que incluem as curtidas e suas derivações (por exemplo, “amei”, “haha”, “uau”, “triste”, “grr”); de compartilhamentos e comentários. Além disso, consideramos o tema das postagens e sua classificação de acordo com os critérios de sustentabilidade (Sachs, 2002). 


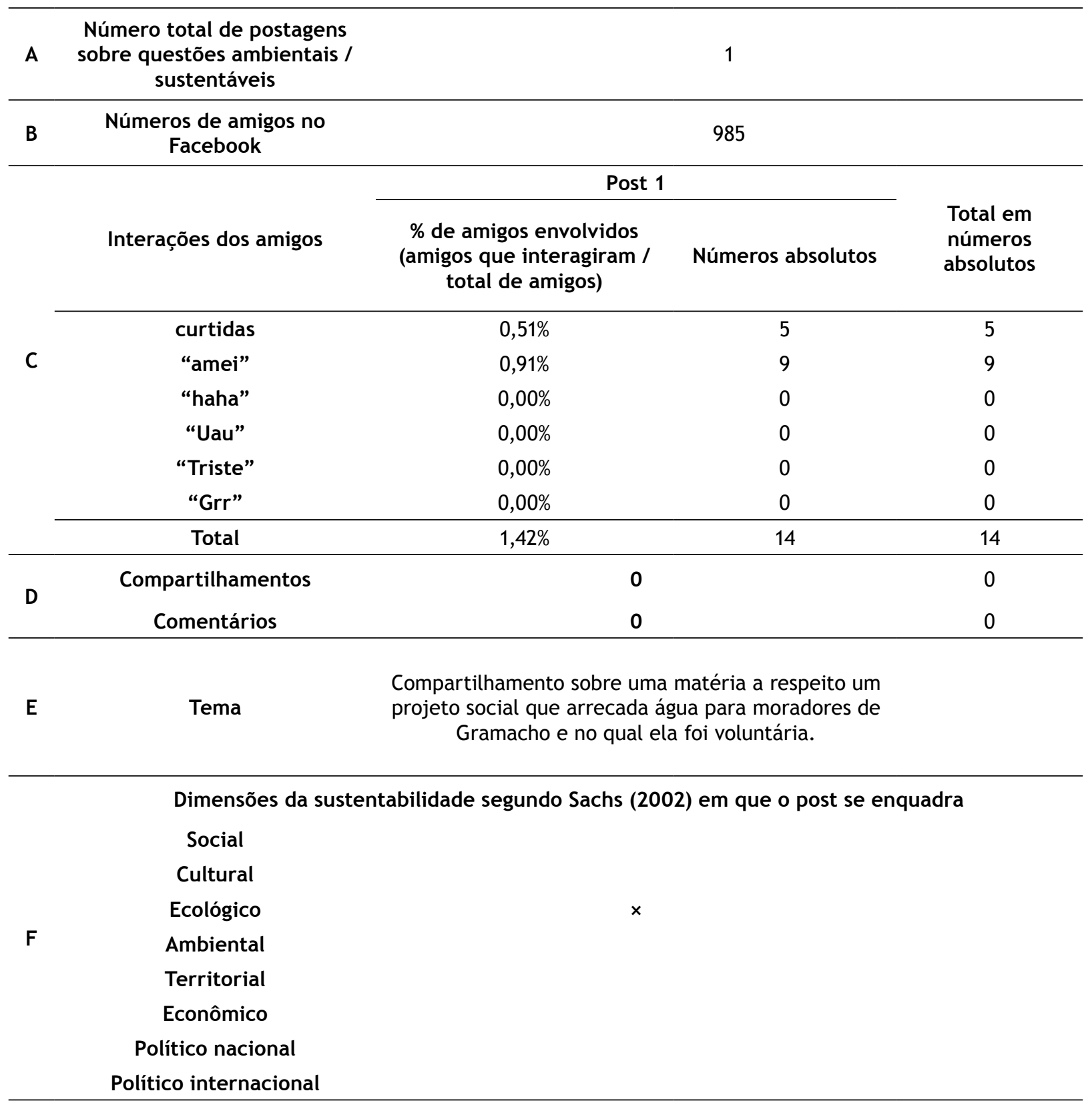

Figura 3. Exemplo de análise e interpretação da linha do tempo.

Fonte: adaptado de Ronfini (2018, p. 65).

\section{Resultados}

A análise permitiu organizar as temáticas ambientais em que pudemos observar sentimentos, percepções e juízos dos jovens, e a influência do contexto em (1) agendamento da mídia; (2) vegetarianismo e veganismo; (3) papel da educação; (4) áreas verdes; (5) confronto entre engajamento e otimismo em oposição ao pessimismo. Não foi possível estabelecer relações entre os resultados e o pertencimento à faixa de renda baixa. Os dados não nos permitiram inferir nada a esse respeito. 


\section{Agendamento da mídia}

Entre os temas que afloraram, o agendamento da mídia foi o mais significativo. Alguns menos engajados relataram que nenhum chegou a cogitar a possibilidade de, por iniciativa própria, fazer posts sobre o meio ambiente porque o assunto não aparecia em seus feeds de notícias e/ou na televisão. A maioria explicitou que o interesse por questões ambientais no Facebook estava associado à cobertura de grandes catástrofes e desastres ambientais pela imprensa. No entanto, houve ação política da parte de outros mais engajados. Quando o então presidente Michel Temer ampliou uma área de exploração mineral na Amazônia, compartilharam, pelo Facebook, uma petição contra o decreto, com adesão expressiva de "amigos". Outros, quando da tragédia ambiental causada pela Samarco em Mariana, fizeram várias postagens sobre o tema.

A relativa passividade dos jovens diante do agendamento pela mídia surpreendeu. Dado que as redes sociais são ambientes virtuais de compartilhamento de ideias, o fato de as discussões sobre o meio ambiente provirem de fontes institucionais sugerem baixo engajamento político.

\section{Vegetarianismo e veganismo}

Assunto menos discutido, mas significativo, o vegetarianismo e o veganismo estiveram presentes nas falas de quatro jovens. Alguns fizeram postagens por terem interesse em dietas mais saudáveis e em defesa dos animais. Outros, inclusive, destacaram os malefícios da indústria da carne em seus posts, rendendo respostas beligerantes.

\section{Papel da educação}

Figura recorrente foi o papel do professor na conscientização ambiental da juventude. Alguns jovens disseram que seus professores costumavam postar questões sobre isso no Facebook. Outros, indicaram também amigos que postam sobre o tema. Para a maioria dos jovens que se manifestou a respeito, o papel da educação formal na questão da conscientização ambiental e a difusão do debate pelas redes sociais são muito importantes.

\section{Proximidade de áreas verdes}

A proximidade geográfica com áreas verdes, como florestas e cachoeiras, foi outro tema de interesse. Poucos jovens, ligados à organização não governamental (ONG) Associação Internacional de Desenvolvimento Econômico InterAmbiental (Aideia), localizada na Ecovila El Nagual, explicaram que viver junto à natureza afeta positivamente o seu interesse por questões ambientais. Mesmo aqueles que moram ou moraram em regiões próximas à natureza e, numa primeira abordagem, não se mostraram atuantes politicamente, mencionaram "amigos" ativistas, reconhecendo a importância do tema em suas vidas.

\section{Confronto entre engajamento $e$ otimismo em oposição ao pessimismo}

A grande maioria dos entrevistados relatou algum tipo de interesse pelas questões ambientais. Muitos disseram que seus "amigos" no Facebook não estavam interessados pelo tema. Confirmando essa percepção, a maioria obteve baixas taxas de interação por parte de seus "amigos". Comentários e compartilhamentos geralmente só aconteceram em posts de fotos em que os sujeitos expressavam, também nas legendas, questões ambientais. Se uns pensam que postar sobre o meio ambiente não adianta muito, outros creem que o Facebook pode ser um importante meio de discussão ou ajuda a despertar paulatinamente $o$ interesse pela ecologia.

É digno de nota que, mesmo entre os mais engajados, a maior parte das publicações sobre questões ambientais é de compartilhamentos, muitas vezes sem que os jovens escrevam textos para acompanhá-los. As ações comunicativas mais efetivas que encontramos foram as fotos postadas junto com legendas, as quais indicavam uma conexão com a natureza.

\section{Discussão}

Gostaríamos de destacar os resultados mais relevantes. Em primeiro lugar, o agendamento da mídia: muitos dos jovens justificaram não postar sobre questões ambientais pelo fato de a mídia não os 
abordar. Outro fato sugestivo é a apatia e o desinteresse, pois praticamente não observamos jovens que produziam conteúdo próprio sobre a questão ambiental, ou agiam politicamente, apesar de alguns terem assinado petições (Ronfini, 2018). Num mundo em que a juventude vem despontando nas redes sociais com milhares e até milhões de seguidores, YouTubers jovens, como Kéfera Buchmann e Whindersson Nunes (Kiuchi, Oliveira Silva, e Riente R. Gomes, 2018; Espinosa, 2016; Faria e Marinho, 2017), mostram que é possível criar conteúdo, mesmo sem grandes recursos tecnológicos.

0 fato de termos descoberto somente um grupo ativista ambiental com prevalente participação jovem sugere também que, contrariamente às pesquisas de Matos (2012), Zanella e colaboradoras (2013), Calado e Camarotti (2013), Viana (2010) e Peruzzo (2013), ao menos entre os jovens com os quais compartilhamos ideias, a questão da ação política e pedagógica ambiental não está na ordem do dia. Encontramos um engajamento limitado com a oNG Aideia, que tem "por objetivo a preservação/proteção, educação, restauração, estudo/pesquisa e, consequentemente, a transformação e o desenvolvimento local" (s. d., s. p.). Podemos observar, na página de Facebook, que essa onG, dentre outras coisas, realiza atividades de conscientização ambiental nas escolas da região, reforçando a problemática educativa já levantada por Matos (2012) e por Zanella e colegas (2013).

Tudo indicou, portanto, atividade político-ambiental baixa ou nula, apesar da existência da oNG mencionada. Consideramos inquietante esse desinteresse, ainda que tenhamos consciência das limitações de se fazerem estudos qualitativos com poucos sujeitos. Ainda assim, como filtramos as questões de uma rede significativa de jovens, o aparente desinteresse pelos debates sobre problemas ambientais e a defesa da natureza geram questionamentos. Lembramos ainda que, tendo escolhido jovens de baixa renda, que são os que mais sofrem com as consequências dos desastres ambientais e do descaso das autoridades (notadamente com relação às incidências negativas sobre a saúde das populações das favelas e dos bairros periféricos), a passividade socioambiental causa perplexidade. Por qual moti- vo não vêm produzindo conteúdo próprio sobre o meio ambiente? Se há tantos jovens que falam nas redes sociais a respeito de temas como maquiagem, estilo de vida, humor, relacionamento e tecnologia, por que não os observamos debatendo o meio ambiente? Por que esse desinteresse geral pelas questões ambientais?

É árdua a tarefa de confrontar nossos resultados e discuti-los, pois, como indicamos no início do artigo, são escassos os estudos. Do ponto de vista estritamente empírico, ainda que Matos (2012) tenha destacado a participação histórica dos jovens nos movimentos ambientais, que Zanella e colaboradoras (2013) tenham discutido o empoderamento juvenil, que Calado e Camarotti (2013) tenham apresentado programas sociais de apoio aos jovens e que Viana (2010) e Peruzzo (2013) tenham sublinhado o protagonismo da juventude em manifestações políticas, somente Pinheiro (2013) discutiu uma temática semelhante à nossa. Sua pesquisa sobre o movimento Twitter @JuventudeRio20 foi iniciativa de caráter institucional que, reconhecemos, gerou mobilização juvenil no âmbito da conferência Rio+20 entre as classes médias, embora não tenha mobilizado as camadas mais pobres da população. Ou seja, a falta de interesse dos jovens em rede pelo meio ambiente parece não se limitar somente a essas camadas, mas à sociedade como um todo $\mathrm{e}$ à comunidade acadêmica em particular. As razões dessa lacuna científica (Sandberg e Alvesson, 2011) e, talvez, de alienação ambiental precisam, portanto, ser elucidadas. Quando será a hora desse debate, não sabemos, mas a greve de caminhoneiros ocorrida em maio de 2018 no Brasil, a qual causou desabastecimento em todo o país e desorganizou a cadeia de produção de alimentos, sugere que seja hora de essas questões entrarem em pauta.

\section{Conclusão}

No que tange aos aspectos empíricos, nosso estudo é único e, apesar dos limites apontados, levanta questões que julgamos significativas. Quanto à abordagem teórica, a pesquisa trouxe uma contribuição interdisciplinar ao integrar o campo psicossocial da comunicação (Ecologia dos Sentidos) 
com o do meio ambiente (critérios de sustentabilidade) para se compreender a integralidade ecológica dos jovens em termos simbólicos (de suas representações e imagens de mundo) em relação ao meio ambiente natural e histórico-cultural em que vivem. Esse quadro psicossocial interdisciplinar levou a uma abordagem metodológica que merece comentários, como o caso da utilização de videoconferências. Pesquisadores como Kohl e Gotzenbrucker (2014) e Lara e Campos (2016), já tinham desenvolvido entrevistas por esse meio, assim como Deakin e Wakefield (2014), e Janghorban, Roudsari e Taghipour (2014), que reforçam as vantagens de se buscar sujeitos virtualmente. Para os autores, ao romper distâncias, investigações que não contam com grandes recursos financeiros são viabilizadas. Empregamos soluções criativas e de baixíssimo custo, que compartilhamos aqui com outros pesquisadores, como (1) gravação audiovisual de entrevistas por meio do "Estúdio de Criação" do YouTube, que permite registrar o que se passa na tela de um computador; (2) entrevistas sonoras por WhatsApp, que podem ser facilmente transcritas com a ajuda de um aplicativo gratuito chamado "Audio to text para WhatsApp".

À guisa de conclusão, acreditamos que este artigo, ainda que modestamente, contribui para o estabelecimento de relações entre juventude, meio ambiente e redes sociais. Isso não somente pela temática ecológica em si, mas notadamente pelo fato de as redes serem hoje, como se sabe, nichos de transformação sociopolítica. Tanto as ações em rede que produzem revoluções como a inação de jovens que não se mobilizam são fundamentais para que possamos compreender seus sentimentos, percepções e razões que expressam a respeito do meio ambiente. Apesar de não termos evidências de se os jovens com quem compartilhamos discussões podem ser tomados como um retrato da juventude de baixa renda do Grande Rio, terminamos este texto com uma certa perplexidade diante dos resultados. Por que, afinal, esses jovens oriundos de um ambiente natural e social que promoveu a primeira grande conferência internacional sobre a ecologia - o icônico Rio de Janeiro -, a qual transformou positivamente o movimento internacional pela defesa do planeta, se calam?

\section{Referências}

Abramo, H. W. (1997). Considerações sobre a tematização social da juventude no Brasil. Revista Brasileira de Educação, 6, 25-36. http://proex.pucminas.br/sociedadeinclusiva/ Blog_Direito_de_se_Diferente/Considerações sobre a Tematização Social da Juventude no Brasil.pdf

Aideia. Aideia - Sobre. Recuperado de https:// Www.Facebook.Com/Pg/Anjosdanatureza1

Associação Internacional de Desenvolvimento Econômico Interambiental. Sobre Nós. Recuperado de https://ongaideia.wordpress. com/sobre/ong-a-ideia/

Baltar, F. e Brunet, I. (2012). Social research 2.0: virtual snowball sampling method using Facebook. Internet Research,22(1), 57-74. Dol: 10.1108/10662241211199960

Banks, A. (2015). 2015 Brazil Digital Future in Focus. Disponível em https://www. comscore.com/Insights/Presentationsand-Whitepapers/2015/2015-Brazil-DigitalFuture-in-Focus

Bauman, Z. (2005). Vidas desperdiçadas. Tradução de Carlos Alberto Medeiros. Rio de Janeiro: Jorge Zahar.

Bourdieu, P. (1983). Questões de Sociologia. Tradução de Jeni Vaitsman. Rio de Janeiro: Editora Marco Zero.

Burg, A. P., Ronfini, N. e Campos, M. N. (2017). Journalisme liquide: Méga-événements au Brésil et nouveaux médias. Argumentum: Journal the Seminar of Discursive Logic, Argumentation Theory \& Rhetoric, 15(1), 2769. Recuperado de https://www.fssp.uaic.ro/ argumentum/Numarul\%2015\%20issue\%201/02 Burg_Ronfini_Campos_tehno.pdf

Calado, K. de A. e Camarotti, M. De F. (2013). Protagonismo Juvenil: um ensaio de participação do Programa Projovem Adolescente de 
Borborema-PB. Revista do PPGEA/FURG-RS, 30(2), 274-289. Recuperado de https://www.seer. furg.br/remea/article/view/3909/2477

Campos, M. N. (2015a). Traversée: Essai sur la communication. Berne: Peter Lang, Éditions Scientifiques Internationales.

Campos, M. N. (2015b). Integrando Habermas, Piaget e Grize: contribuições para uma Teoria Construtivista-Crítica da Comunicação. Revista Famecos, 21(3), 966-996. Recuperado de http://revistaseletronicas.pucrs.br/ojs/index. php/revistafamecos/article/view/18777/12572

Campos, M. N. (2017). Navegar é preciso, comunicar é impreciso. São Paulo: Edusp.

Campos, M. N. e Grabovschi, C. (2011). Argumentação e design: Cognição, afetividade e moralidade em comunidades universitárias de aprendizagem. Revista Educação e Cultura Contemporânea, 8(17), 1-27. Recuperado de http://revistapuca.estacio.br/index.php/ reeduc/article/viewArticle/172

Castilho, L. V. de, Oliveira, P. M. de C. e Fabriani, C. B. (2012, setembro). Análise de uma tragédia ambiental e a participação da população no equacionamento dos problemas de moradia: um estudo de caso da tragédia na região serrana do Rio de Janeiro. VI Encontro Nacional da anPPAS. Belém, Pará, Brasil. Recuperado de http://www.anppas.org.br/encontro6/anais/ ARQUIVOS/GT11-1191-954-20120622101303.pdf.

Deakin, H. e Wakefield, K. (2014). Skype interviewing: reflections of two $\mathrm{PhD}$ researchers. Qualitative Research, 14(5-9), 603-616. DOI: 10.1177/1468794113488126

Ellison, N. B., Steinfield, C. e Lampe, C. (jul. 2007). The Benefits of Facebook "Friends": Social Capital and College Students' Use of Online Social Network Sites. Journal of ComputerMediated Communication, 12(4), 1143-1168. DOI: 10.1111/j.1083-6101.2007.00367.x

Espinosa, J. R. (2016). Youtubers teen: a influência dos vlogs às novas gerações. Rio de Janeiro: Universidade Federal do Rio de Janeiro. Recuperado de http://pantheon.ufrj.br/bitstream/11422/1342/3/JREspinosa.pdf
Facebook. (25 jun. 2017). Como faço para publicar na minha Linha do Tempo? | Central de ajuda do Facebook. Recuperado de https://www. facebook.com/help/170116376402147?helpr ef=faq_content

Faria, A. C. G. e Marinho, F. H. (2017, setembro). Influenciadores digitais: Um estudo sobre a populariade alcançada através do YouTube. Em Intercom - Sociedade Brasileira de Estudos Interdisciplinares da Comunicação, $40^{\circ}$ Congresso Brasileiro de Ciências da Comunicação, Curitiba, Brasil. Disponível em http://portalintercom.org.br/anais/nacional2017/resumos/R12-1865-1.pdf

Foracchi, M. M. (1965). O estudante e a transformação da sociedade brasileira. São Paulo: Companhia Editora Nacional.

Freitas, H. et al. (2000). O método de pesquisa survey. Revista de Administração, 35(3), 105112. Recuperado de http://www.utfpr.edu. br/curitiba/estrutura-universitaria/diretorias/ dirppg/especializacoes/pos-graduacao-dagee/ lean-manufacturing/PesquisaSurvey012.pdf

Fundação Cecierj e Consórcio Cederj. (2018). Conheça o Pré-vestibular Social. Recuperado de http://cederj.edu.br/prevestibular/ conheca-o-pvs/

Fundo de População das Nações Unidas. (2014). Situação da População Mundial 2014. Recuperado de http://unfpa.org.br/Arquivos/ swop2014.pdf

Glaser, B. G. e Strauss, A. L. (1967). The Discovery of Grounded Theory: Strategies for Qualitative Research (vol. 1). New York: Aldine Transcription. Dol: 10.2307/2575405

Grize, J.-B. (1996). Logique naturelle et communications. Paris: Presses Universitaires de France.

Grize, J.-B. (1997). Logique et langage. Paris: Ophrys.

Handcock, M. S. e Gile, K. J. (2011). On the Concept of Snowball Sampling. Sociological Methodology, 41(1), 367-371. Dol: 10.1111/j.1467-9531.2011.01243.x 
Instituto Brasileiro de Geografia e Estatística. (2017). Sumário das tabelas disponíveis. Recuperado de http://www.ibge.gov.br/home/ estatistica/indicadores/trabalhoerendimento/ pme_nova/defaulttab_hist.shtm

Janghorban, R., Roudsari, R. L. e Taghipour, A. (2014). Skype interviewing: The new generation of online synchronous interview in qualitative research. International Journal of Qualitative Studies on Health and Well-being, 9(1), 24152. https://doi.org/10.3402/qhw.v9.24152

Kohl, M. M. e Gotzenbrucker, G. (2014). Networked technologies as emotional resources? Exploring emerging emotional cultures on social network sites such as Facebook and Hi5: a trans-cultural study. Media, Culture \& Society, 36(4), 508-525. Dol: $10.1177 / 0163443714523813$

Kiuchi, C., Oliveira Silva, J. e Riente R. Gomes, L. (2018). Youtubers: a nova geração de influenciadores. Revista Científica umc, 3(1), 1-14. http://seer.umc.br/index.php/revistaumc/ article/view/214/191

Lara, M. G. J. de e Campos, M. N. (2016). Les amitiés brisées, Facebook et les élections brésiliennes 2014. TrajEthos, 11(55), 105-146. http:// www.trajethos.ca/files/7414/8202/4102/ LARA_CAMPOS_TrajEthos_51.pdf

Lévy, P. (1999). Cibercultura. Tradução de Carlos Irineu Da Costa. São Paulo: Editora 34.

Manzini, E. J. (2003). Considerações sobre a Elaboração de Roteiro para Entrevista SemiEstruturada. Em M. C. Marquezine, M. A. Almeida e S. Omote (orgs.), Colóquios sobre pesquisa em educação especial, Londrina, Brasil. Disponível em https://www.marilia.unesp.br/Home/Instituicao/Docentes/ EduardoManzini/Consideracoes_sobre_a_elaboracao_do_roteiro.pdf

Manzini, E. J. (2004). Entrevista semi-estruturada: análise de objetivos e de roteiros. Seminário in- ternacional sobre pesquisa e estudos qualitativos, Bauru. USC. CD-ROOM. ISBN:85-98623-01-6. 10p

Manzini, E. J. (2012). Uso da entrevista em dissertações e teses produzidas em um programa de pós-graduação em educação. Revista Percurso - NEMO, 4(2), 149171. Recuperado de http://repositorio. unesp.br/bitstream/handle/11449/114753/ ISSN21773300-2012-04-02-149-171. pdf?sequence $=1$ \&isAllowed $=y$

Margulis, M. e Urresti, M. (2008). La juventud es más que una palabra. Em M. Margulis, (ed.), La juventud es más que una palabra: Ensayos sobre cultura y juventud ( $3^{\mathrm{a}}$ ed., pp. 13-30). Buenos Aires: Editora Biblos Socied.

Matos, Z. M. R. (2012). Aprender participando: uma experiência fora da sala de aula para a formação de sujeitos sócias em Brasil. Aula, 18, 141-154. Disponível em https://gredos. usal.es/bitstream/handle/10366/130730/ Aprender_participando_una_experiencia_ pa.pdf?sequence $=1$

ONU Brasil. (2014). População jovem é a chave para o desenvolvimento mundial, revela uNFPA [Página web]. ONU Brasil. Disponível em https://nacoesunidas.org/populacao-joveme-a-chave-para-o-desenvolvimento-mundialrevela-unfpa/

Painel Intergovenamental sobre Mudanças Climáticas. (2012). Managing the Risks of Extreme Events and Disasters to Advance Climate Change Adaptation. Cambridge, Nova lorque, Melborne, Madri, Cape Town, Singapura, São Paulo Delhi, Toquio, Cidade do Mexico: Cambridge University Press. Disponível em https://www.ipcc.ch/pdf/special-reports/ srex/SREX_Full_Report.pdf\%5Cnpapers2:// publication/uuid/41AD43FB-2529-4ACD-AD334C2D0AB4A0F3\%5Cnhttp://ipcc-wg2.gov/SREX/

Pempek, T. A., Yermolayeva, Y. A. e Calvert, S. L. (2009). College students' social networking 
experiences on Facebook. Journal of Applied Developmental Psychology, 30(3), 227-238. Dol: 10.1016/j.appdev.2008.12.010

Pero, V. e Mihessen, V. (2013). Mobilidade urbana e pobreza no Rio de Janeiro. Revista Econômica, 15(2), 77-100. http://www.revistaeconomica.uff.br/index.php/revistaeconomica/ article/view/71/186

Peruzzo, C. (2013). Movimentos sociais, redes virtuais e mídia alternativa no junho em que "o gigante acordou” (?). Matrizes, 7(2), 73-93. Recuperado de http://www.revistas.usp.br/ matrizes/article/view/69407/71976

Pinheiro, M. de A. (2013). Meio ambiente e mobilização nas redes sociais. Em C. F. Musse e P. M. da Silveira Jr. (eds.), Comunicação: redes, jornalismo, estética e memória (pp. 69-80). Rio de Janeiro: Mauad X.

Puff, J. (2017). Saúde pública: Como o RJ chegou a uma de suas piores crises no ano dos Jogos. Recuperado de http://www.bbc.com/portuguese/noticias/2016/01/160106_crise_economica_rio_jp

Recuero, R. (2014). Curtir, compartilhar, comentar: trabalho de face, conversação e redes sociais no Facebook. Verso e Reverso, 28(68), 114-124. Recuperado de http://www.revistas.unisinos. br/index.php/versoereverso/article/view/7323

Robards, B. e Bennett, A. (2011). MyTribe: Postsubcultural Manifestations of Belonging on Social Network Sites. Sociology, 45(2), 303-317. Dol: $10.1177 / 0038038510394025$

Ronfini, N. (2018). Cara, tem um lixo do teu lado: Sentimentos e juízos da juventude do Grande Rio sobre o meio ambiente, em comunidades em rede no Facebook. Rio de Janeiro: Universidade Federal do Rio de Janeiro.

Ross, C. et al. (2009). Personality and motivations associated with Facebook use. Computers in Human Behavior, 25(2), 578-586. Dol: 10.1016/j. chb.2008.12.024
Sachs, I. (2002). Caminhos para o Desenvolvimento Sustentável. Rio de Janeiro: Garamond.

Sandberg, J. e Alvesson, M. (2011). Ways of constructing research questions: gap-spotting or problematization? Organization, 18(1), 23-44. DOI: $10.1177 / 1350508410372151$

Sandelowski, M. (2000). Combining qualitative and quantitative sampling, data collection, and analysis techniques in mixed-method studies. Research in nursing \& health, 23, 246-255. Dol: https://doi. org/10.1002/1098-240X(200006)23:3<246::AIDNUR9>3.0.CO;2-H

Silva, A. P. e Gonzales, W. (2016). Facebook e participação política: o que dizem os jovens do \#OcupaAlemão. Horizontes, 34(1), 159172. https://revistahorizontes.usf.edu.br/ horizontes/article/view/337

Silva, R. S. da; Silva, V. R. da. (2011). Política nacional de juventude: trajetória e desafios. Caderno CRH, 24(63), 663-678. Recuperado de http://www.scielo.br/pdf/ccrh/v24n63/13.pdf

Sposito, M. P. (1997). Estudos sobre Juventude em educação. Revista Brasileira de Educação, 5/6(5), 37-52. Recuperado de http://www.feis. unesp.br/Home/DSAA/DSAA/ProjetoGQT-SCM/ documentos/educacao/educa\%E7\%E3o e juventudeMARILIA_PONTES_SPOSITO.pdf

Viana, N. (2011, novembro). Juventude, Contestação, Autogestão. Subalternidade, trânsitos e cenários. Em /l Simpósio de Ciências Sociais, Goiás, Brasil. Disponível em http://s3.amazonaws. com/academia.edu.documents/30471098/ Juventude_Contestacao_e_Autogestao_-Texto_completo.pdf?AWSAccessKeyld=AKIAIW OWYYGZ2Y53UL3A\&Expires=1487604372\&Sig nature $=u N G c E V y O B H b i B a B h A E u Q j C p l L g l \% 3 D$ \&response-content-disposition=inline\%3B filen

Wellman, B. et al. (2001). Does the Internet Increase, Decrease, or Supplement Social Capital? American Behavioral Scientist, 45(3), 436-455. Dol: 10.1177/00027640121957286 
World Commission on Environment and Development. (1987). Our Common Future. Oxford: Oxford University Press.

Yin, T. K. (2001). Estudo de caso: planejamento e métodos ( $2^{\mathrm{a}} \mathrm{ed}$.). Porto Alegre: Bookman.
Zanella, A. V. et al. (2013). Jovens, juventude e políticas públicas: produção acadêmica em periódicos científicos brasileiros (2002 a 2011). Estudos de Psicologia, 18(2), 327-333. Dol: 10.1590/S1413-294X2013000200019 